\title{
ECOLOGICAL GENETICS OF MANIOLA JURTINA L. ON THE ISLES OF SCILLY
}

\author{
W. H. DOWDESWELL \\ Biology Department, Winchester College \\ and \\ E. B. FORD \\ Genetic Laboratories, Zoology Department, Oxford
}

Received $15 \cdot x \cdot 54$

WE have already shown that the distribution of spots on the under-side of the hind-wings of the butterfly Maniola jurtina provides a reliable means of quantifying variation in both sexes, and that it can be used as an index of evolutionary divergence in different colonies (1;2;3). In the male, spotting proved to be uniform throughout the islands studied and similar to that of the mainland populations. Spotdistribution in the females, however, was very variable and quite distinct from that found in the rest of England. While the three large islands (St Mary's, Tresco and St Martin's) all showed similar values, a number of smaller ones (the areas of which are one-seventeenth or less those of the large), exhibited a great diversity of spotting, each being characterised by a particular type of spot-distribution (3).

One of the main objects of our work in the Scillies during August I953 was to discover whether the characteristics of the various island populations had changed appreciably during the two years which had elapsed since our previous visit.

\section{THE SMALL ISLANDS \\ (a) Females}

Samples of the female populations on a number of the small islands taken in I95 I and 1953 are compared in table $\mathrm{I}$.

It will be seen that, with one exception (Tean area 5, see map), there is no significant difference in spotting between the two years. In other words, spot-distribution on these small islands must have been stabilised during the period between successive samples. For Tean area I our information is more extensive and dates back to 1946. A table of general contingency for samples of females taken in 1946, I950, I95 I and 1953 gives $\chi_{(9)}^{2}=7.2$ for which $\mathrm{P}=0.7$ to 0.5 . There is thus good reason for assuming that the population has remained stable in respect of spotting for a period of eight years.

The situation on Tean area 5 is of interest. Our collecting in I95I had shown for the first time that a significant difference existed between the populations of areas $\mathrm{I}$ and 5, which had been similar in I950 (3). Clearly, some effective ecological barrier now existed between them. This was undoubtedly area 4 , a tongue of windswept 
ground about 120 yards long and 60 yards wide with short, close turf and stunted plants such as Lotus corniculatus. Careful observation had shown that although the butterflies frequently set out from both

\section{TABLE I}

Spot-distribution in female Maniola jurtina on the small islands in 1951 and 1953

\begin{tabular}{|c|c|c|c|c|c|c|c|c|c|}
\hline & & \multicolumn{6}{|c|}{ Spots } & \multirow{2}{*}{ Total } & \multirow{2}{*}{ Difference } \\
\hline & & 0 & I & 2 & 3 & 4 & 5 & & \\
\hline $\begin{array}{c}\text { St Helens (1951) } \\
", \quad(1953)\end{array}$ & $\dot{\bullet}$ & $\begin{array}{l}26 \\
46\end{array}$ & $\begin{array}{l}41 \\
53\end{array}$ & $\begin{array}{l}64 \\
65\end{array}$ & $\begin{array}{l}18 \\
14\end{array}$ & $\begin{array}{l}3 \\
2\end{array}$ & $\begin{array}{l}\mathbf{I} \\
\mathbf{0}\end{array}$ & $\begin{array}{l}153 \\
180\end{array}$ & \} $\begin{array}{l}\text { N.S. }\left(x_{(3)}^{2}=5.80 ; P=\right. \\
0.1 \text { to } 0.2)\end{array}$ \\
\hline $\begin{array}{cc}\text { Tean Area } & 5(1951) \\
" & 5(1953)\end{array}$ & $\dot{\cdot}$ & $\begin{array}{l}49 \\
30\end{array}$ & $\begin{array}{l}12 \\
14\end{array}$ & $\begin{array}{l}42 \\
54\end{array}$ & $\begin{array}{r}3 \\
13\end{array}$ & $\begin{array}{l}4 \\
3\end{array}$ & $\begin{array}{l}\mathbf{I} \\
\mathbf{0}\end{array}$ & $\begin{array}{l}I I x \\
I 14\end{array}$ & \} S. $\underset{\substack{\left(\chi_{(2)}^{2} \\
0.02\right)}}{\left(\chi^{2}\right)}=8.02 ; \quad P=$ \\
\hline 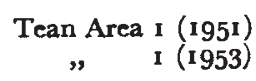 & $\dot{.}$ & $\begin{array}{l}33 \\
32\end{array}$ & $\begin{array}{r}9 \\
\mathbf{1} 1\end{array}$ & $\begin{array}{l}40 \\
46\end{array}$ & $\begin{array}{l}13 \\
21\end{array}$ & $\begin{array}{l}7 \\
3\end{array}$ & $\begin{array}{l}\mathbf{I} \\
\mathbf{I}\end{array}$ & $\begin{array}{l}103 \\
I I 4\end{array}$ & N.S. \\
\hline $\begin{array}{l}\text { Arthur (1951) } \\
\quad, \quad(1953)\end{array}$ & $\dot{\bullet}$ & $\begin{array}{l}8 \\
5\end{array}$ & $\begin{array}{l}5 \\
5\end{array}$ & $\begin{array}{l}36 \\
44\end{array}$ & $\begin{array}{l}\text { I } 1 \\
\text { I } 8\end{array}$ & $\begin{array}{l}4 \\
4\end{array}$ & $\begin{array}{l}\mathbf{0} \\
\mathbf{I}\end{array}$ & $\begin{array}{l}64 \\
77\end{array}$ & N.S. \\
\hline 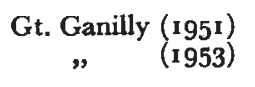 & $\dot{.}$ & $\begin{array}{l}41 \\
32\end{array}$ & $\begin{array}{r}7 \\
13\end{array}$ & $\begin{array}{l}37 \\
52\end{array}$ & $\begin{array}{l}8 \\
6\end{array}$ & $\begin{array}{l}5 \\
2\end{array}$ & $\begin{array}{l}0 \\
0\end{array}$ & $\begin{array}{r}98 \\
r 05\end{array}$ & $\left\{\begin{array}{l}\text { N.S. }\left(x_{(2)}^{2}=3.5^{8} ; \mathrm{P}=\right. \\
0.1 \text { to } 0.2)\end{array}\right.$ \\
\hline
\end{tabular}

In the column for Difference, N.S. denotes " Not Significant" and S. denotes "Significant". Figures for $\chi^{2}$ are included where there is any question of doubt.

ends as if to cross this area, they always turned back after flying about Io yards from the extremities. We never saw a jurtina in the middle of area 4. These observations were confirmed by marking

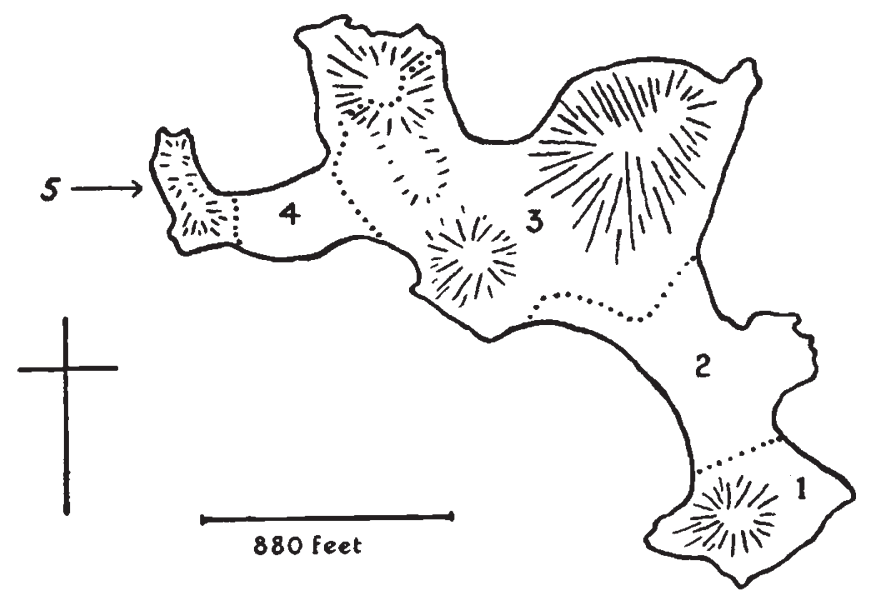

MAP.-Tean (Isles of Scilly). Boundaries of collecting areas . . . . . .

individuals in areas 3 and 5 with distinctive colours. No interchange was detected in the relatively large samples subsequently caught (including almost the whole of the population in area 5). 
On revisiting Tean in I953, it was at once obvious that the grass in area 4 was longer than ever before and was now at least six inches high. The reasons for this change were not far to seek. For some years the island had been continuously grazed by a herd of cattle, but these were removed in the late summer of $195^{\circ}$ and not replaced. Their absence made little difference to the vegetation during ${ }^{195} \mathrm{I}$ but by 1953 its increase was most striking. $M$. jurtina of both sexes could now be seen flying across area 4 in either direction, obviously gaining adequate shelter from the wind. It seems clear that the changed ecological conditions had been responsible for the alteration in spotting during the two intervening years, and it is not surprising to find that the populations in areas $I$ and 5 are now identical (see table I). The difference between them was measured by $\chi_{(3)}^{2}=9 \cdot 2$ in $195^{1}$, and by $\chi_{(3)}^{2}=3.00$ in 1953 .

\section{(b) Males}

The only sample collected on a small island was from Tean area I (see table 2).

TABLE 2

Spot-distribution in male Maniola jurtina on a small island

in 1951 and 1953

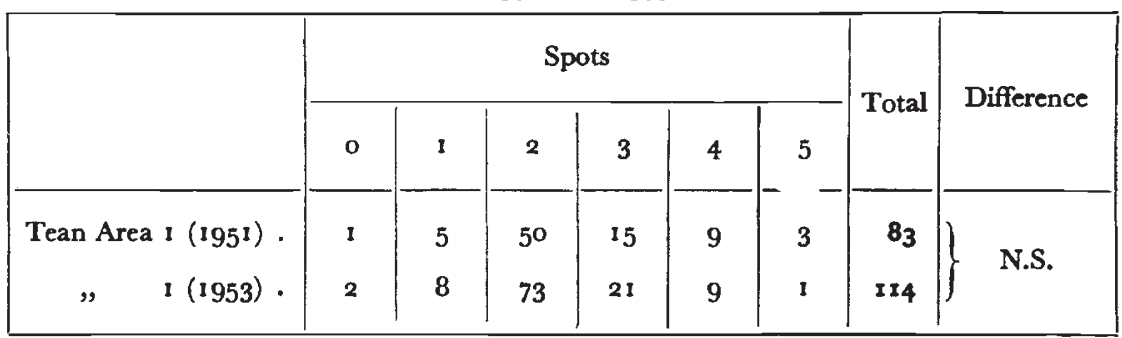

Clearly, the two are similar in spot-distribution. Owing to shortage of time, due to other work on which we were engaged, we thought it worth while only to obtain this one sample taken on the island where we camped. For we had already found (3) that the male spotdistribution is the same on all the islands mentioned in this section, large and small, and that this accords with its frequency-distribution throughout southern England. Thus we felt that its lack of variation from one locality to another, which contrasts so strikingly with the female situation, justified us in omitting further male counts this year, except for occasional checks such as the one included here and the samples taken on St Martin's (p. 268) and on Samson (pp. 270-1).

\section{THE LARGE ISLANDS}

(a) Females

Sampling in 1953 was confined to St Martin's (see table 3). Evidently there is no indication of divergence between the two years. Furthermore, a table of general contingency for samples in 1950, 
I95 I and 1953 gives $\chi_{(4)}^{2}=\mathrm{I} \cdot 9 ; \mathrm{P}=0.8$ to 0.7 . Hence we are justified in assuming stability in the female population on the central area of St Martin's over a period of four years. Collecting in 1950 also established a similarity in female spotting between St Martin's and Tresco which remained unaltered in $195 \mathrm{I}$, when it was also found to be similar to that on St Mary's $(2 ; 3)$. Lack of time prevented us from obtaining samples on Tresco and St Mary's in I953.

TABLE 3

Spot-distribution in female Maniola jurtina on a large island in 1951 and 1953

\begin{tabular}{|c|c|c|c|c|c|c|c|c|}
\hline & \multicolumn{6}{|c|}{ Spots } & \multirow{2}{*}{ Total } & \multirow{2}{*}{ Difference } \\
\hline & $\circ$ & I & 2 & 3 & 4 & 5 & & \\
\hline St Martin's (195I) & 38 & 38 & 33 & 5 & 2 & o & 116 & N.S. $\left(\chi^{2}=0.92\right.$; \\
\hline$" \quad(\mathrm{r} 953)$ & 46 & 34 & $3^{6}$ & 3 & I & o & 120 & $P=0.7$ to 0.5$)$ \\
\hline
\end{tabular}

(b) Males

We took a small sample of males from St Martin's in 1953. The spot-distribution proved to be quite typical and served to confirm our view that male spotting is stabilised on all the islands we have visited so far, both large and small (see table 4).

TABLE 4

\begin{tabular}{|c|c|c|c|c|c|c|c|c|}
\hline & \multicolumn{6}{|c|}{ Spots } & \multirow{2}{*}{ Total } & \multirow{2}{*}{ Difference } \\
\hline & 0 & I & 2 & 3 & 4 & 5 & & \\
\hline St Martin's (195I) & 8 & เ8 & I99. & 43 & 18 & 7 & 293 & N.S. $\left(x_{(2)}^{2}=0.15\right.$; \\
\hline$", \quad(1953)$ & .. & 7 & 37 & 9 & 3 & $\cdots$ & 56 & $P>0 \cdot 9)$ \\
\hline
\end{tabular}

\section{ISLANDS OF INTERMEDIATE SIZE}

It has already been explained that the Isles of Scilly on which we have worked can be classified into large islands, of which there are three (St Martin's, Tresco, St Mary's), with areas of 682 acres or more, and into four small islands with areas of 40 acres or less. The smallest of the large islands (St Martin's) therefore has an area approximately seventeen times greater than the largest of the small (St Helens). The M. jurtina populations are adjusted entirely differently to the conditions obtaining on islands of these two sizegroups. 
Between them, however, are two, Bryher (353 acres) and Samson (8o acres), of intermediate area. It was a matter of much interest, therefore, to determine whether the female spot-distributions of the butterflies inhabiting them conform with the large-island or the smallisland types, or are of a different nature from either.

\section{(a) Bryher}

The northern and southern parts of this island are high, bare, and rocky, and are unsuited to maintaining a jurtina population; the northern end, indeed, consists of a wind-swept heather moor. In the centre, where the village is situated, the ground is low-lying, but it is cultivated; so that there the butterfly maintains itself principally along the edges of fields and the borders of lanes. Consequently, it is uncommon, and the region acts as a partial barrier to the insect. It is, indeed, only along the lower slopes surrounding the southern hill, and the western and eastern sides of the northern one, that it flourishes.

We had sampled one of these communities, that on the east side of the southern hill, in I95 I (3) with the surprising result shown in table 5 : that is to say, the distribution of female spotting descends from a single large mode at o spots, like one half of the normal male distribution, in the same way that it does on the mainland of England eastwards from the border of Cornwall and Devon $(2,3)$. Thus it is entirely distinct from the distribution on the three large islands in Scilly, which all have approximately equal frequencies at o, I, and 2 spots. In I953 we sampled this same population on Bryher again (table 5) and found it to be substantially unchanged $\left(\chi_{(2)}^{2}=2 \cdot 02\right.$, for which $\mathrm{P}>0.3)$, though it is unlike any other known in Scilly.

Lack of time had in I95I prevented us from examining the ecology of Bryher with respect to $M$. jurtina or sampling a further population there. These defects we remedied in 1953, with the result in regard to habitats already outlined. We captured 106 females from a considerable colony of the butterfly on the west side of the northern plateau, collecting on and around the isolated eminence of Gweal Hill : the data thus obtained are given in table 5 . Here, as will be seen, the spot-distribution is unlike that at the southern end of the island, having a single mode at 2 spots. The difference between the two populations, of course, using the 1953 samples, is significant $\left(\chi_{(2)}^{2}=7 \cdot 27\right.$, for which $\left.\mathrm{P}<0 \cdot 02\right)$. These results suggest that $M$. jurtina on Bryher is split into distinct populations each of them equivalent, in extent and uniformity of environment, to those on two small islands.

That is to say, the insect does not here inhabit an extensive and heterogeneous area, as it does on the large islands. Accordingly, it has become adapted differently in the rather isolated localities in which we found it, for ecologically these are not like one another. That at the southern end consists of little fields of rather long grass 
sheltered by stone walls, and of deep grassy tracks and tiny clearings among tall bramble and bracken. The other, on and around Gweal Hill, is much more exposed, with relatively large areas of grass, larger fields, and much less bracken and bramble.

\section{(b) Samson}

This island of 80 acres is effectively in two parts. Each consists of an oblong conical hill running roughly north and south, the sides of which are covered with tall bracken. Between them is a low flat isthmus of short turf, without bracken, and 75 yards wide. We found a small $M$. jurtina population on steep grassy slopes, relatively free from bracken, at the northern end of the island; and a second among and around the ruins of the deserted village on the summit

TABLE 5

Spot-distribution of female Maniola jurtina on two islands of intermediate size, Bryher and Samson

\begin{tabular}{|c|c|c|c|c|c|c|c|}
\hline & \multicolumn{6}{|c|}{ Spots } & \multirow{2}{*}{ Totals } \\
\hline & o & $\mathbf{I}$ & 2 & 3 & 4 & 5 & \\
\hline $\begin{array}{cc}\text { Bryher, South, } & 951 \\
, " & 953 .\end{array}$ & $\begin{array}{l}5^{1} \\
4^{2}\end{array}$ & $\begin{array}{l}34 \\
3^{1}\end{array}$ & $\begin{array}{l}21 \\
27\end{array}$ & $\begin{array}{l}2 \\
6\end{array}$ & $\begin{array}{l}2 \\
0\end{array}$ & $\begin{array}{l}\circ \\
\circ\end{array}$ & $\begin{array}{l}110 \\
106\end{array}$ \\
\hline Bryher, North, 1953. & 26 & 33 & $4^{6}$ & 3 & $\mathrm{I}$ & o & 109 \\
\hline Samson, North, r 953 & 9 & 7 & 39 & 10 & $\mathbf{I}$ & o & 66 \\
\hline Samson, South, r 953 & 10 & 12 & $3^{8}$ & $\mathrm{I}$ & $\mathbf{I}$ & 0 & 62 \\
\hline
\end{tabular}

of the southern hill, below which we also took a few along the narrow track between the bracken and the shore on the west side.

The elongated summit of the northern hill, on which are situated magnificent Chamber Tombs of the Bronze Age, is covered with short turf; so is the isthmus between the two parts of the island. This turf is quite unsuitable as a habitat for M. jurtina, which is rare or absent in both areas. Indeed, it is of the kind which forms an effective barrier to the insect on Tean.

On Samson, therefore, are two populations of this butterfly, one northern and one southern. They are isolated from one another yet identical (table 5), as formerly were the isolated populations in areas I and 3 on Tean $(1,2)$. It will be obvious that they are of the type in which the female spot-distribution is rather similar to the male, with a single large and clearly marked mode at 2 spots. They must be adjusted to effectively similar conditions, in so far as the multifactorial spot-distribution is an index of such adjustment; and, indeed, the ecology of their habitats does seem to be very much the same. 
Here, as on Bryher, we have not one population of intermediate size between those on the large and small islands, but two small populations which are quite unlike the type with effectively similar frequencies at $\mathrm{O}, \mathrm{I}$ and 2 spots which seems to arise as a compromise to a wide diversity of conditions within a large habitat. Incidentally, it is worth noting that the nearest population to those on Samson is that at the southern end of Bryher, $75^{\circ}$ yards across the sea at high water, and it is very different from them.

We obtained small samples of males from both the northern and southern populations on Bryher, and find that they are quite characteristic of the normal condition in $M$. jurtina. That is to say, they have a single mode at 2 spots (table 6 ) which, being the type found throughout nearly the whole range of the butterfly (3), does not reflect adjustment to different ecological conditions in the way that is indicated so clearly by female spotting.

TABLE 6

Spot-distribution of male Maniola jurtina in two populations on the island of Samson in 1953

\begin{tabular}{|l|c|c|c|c|c|c|c|c|}
\hline & \multicolumn{7}{|c|}{ Spots } & \multirow{2}{*}{ Totals } \\
\hline & 0 & I & 2 & 3 & 4 & 5 & \\
\hline Samson, North & 0 & I & 29 & 14 & 7 & 0 & 5 I \\
\hline Samson, South & 0 & 4 & 40 & 19 & 4 & 0 & 67 \\
\hline
\end{tabular}

\section{SUMMARY}

I. The female spot-distribution of the restricted populations of Maniola jurtina on the small islands in Scilly are, in general, different from one another, but remain constant on each.

2. A single and distinct type of spot-distribution is, however, characteristic of the three large islands of St Martin's, Tresco, and St Mary's. This also remains constant from year to year. It seems to be developed in response to the average of the conditions existing in a considerable and diversified habitat.

3. The small island of Tean now contains two (formerly three) isolated populations. The main one had remained bimodal (with a smaller mode of no spots, and a larger at two) since 1946 . This condition persisted also in 1953.

4. In $195^{I}$, the very small isolated population on area 5 of Tean had become significantly distinct, being bimodal but with the larger mode at o. By 1953 this difference had disappeared. Moreover, we found area 5 no longer isolated from the rest of the island, for the lawn-like turf, unsuited to the butterfly, in the intervening region had grown long, owing to the removal of the cattle which had formerly grazed it. 
5. It was found that two islands of intermediate size (Bryher and Samson) each contained two populations isolated from one another, and occupying limited areas. They, therefore, had the characteristics of those found on the small islands.

6. Thus the female spot-distribution of Maniola jurtina in the Isles of Scilly is maintained at a number of distinct and constant values by selection in response to local conditions. When the conditions change, however, so may the spot-distribution if the area affected be of small size.

\section{REFERENCES}

(1) DOWDESWEll, W. H., FISHER, R. A., AND FORD, E. B. 1949. Heredity, 3, 67-84.

(2) DOWDESWELl, W. H., AND FORD, E. B. 1952. Heredity, 6, 99-IO9.

(3) DOWDESWell, W. H., AND FoRd, E, B. 1953. Symposia Soc. Exp. Biol., 7, 254273. 